\title{
Representações e Atitudes em Sala de Aula quanto às Questões Étnico-Raciais: um estudo de caso ${ }^{1}$
}

\author{
Representations and Attitudes in the Classroom and Ethnic \\ and Racial
}

\author{
Jussara Cristina Barboza Tortella ${ }^{2}$ \\ Eliete Aparecida de Godoy ${ }^{3}$ \\ Artur José Renda Vitorino ${ }^{4}$ \\ Rosana Paes de Santana ${ }^{5}$
}

\section{RESUMO}

Com referência às questões étnico-raciais no contexto escolar, o presente trabalho estabeleceu como objetivos: a) compreender as representações do professor e alunos do Ensino Fundamental sobre as relações étnico-raciais no contexto escolar; b) verificar o conhecimento que o professor possui acerca da Lei $n^{\circ} 10.369 / 2003$ e dos conteúdos relativos à história e cultura africanas; c) analisar as representações do docente e dos discentes diante de uma situação de discriminação étnico-racial. O estudo apresenta a abordagem de pesquisa qualitativa do tipo descritivo. Foram participantes: 1 professora e 21 alunos do quinto ano do Ensino Fundamental. Utilizaram-se, como procedimento, entrevistas semiestruturadas e uma situação-problema seguida de perguntas referentes à mesma. Os resultados indicaram que há pouco conhecimento por parte do professor e dos alunos sobre a história da África. Quanto às questões étnicoraciais, a maioria dos alunos é capaz de identificar situações discriminatórias e julgá-las como ruins.

Palavras-chave: Práticas pedagógicas. Questões étnico-raciais. Formação de professores.

\footnotetext{
10 texto é inédito e não há conflitos de interesse, sendo aprovado pelo Comitê de Ética da área (Universidade São Francisco), sob o protocolo $n^{\circ}$ 0202.0.142.000-09. Os autores trabalharam juntos em todas as etapas de produção do manuscrito.

2 Doutora em Psicologia da Educação pela UNICAMP. Docente no Programa de Pós Graduação em Educação da PUCCampinas.

3 Doutora em Psicologia da Educação pela UNICAMP. Docente na Graduação do GRUPO IBMEC EDUCACIONAL S. A. Campinas.

4 Doutor em História pela UNICAMP. Docente do Programa de Pós Graduação em Educação da PUC-Campinas.

5 Pedagoga pela Universidade São Francisco. Agente de Educação Infantil na Prefeitura Municipal de Campinas.
} 


\section{ABSTRACT}

Considering the ethnic and racial issues in the school context, this work established the following objectives: a) understand the representations of the teacher and elementary school students about the ethnic-racial relations in the school context, b) verify if teachers have knowledge about the law $n$ ㅇ. $10.369 / 2003$ and content related to African history and culture; c) analyzing the representations of teachers and students in a situation of ethnic and racial discrimination. The descriptive study presents a qualitative research approach. The participants were 21 students and a teacher of the fifth year of elementary school. As a procedure, we used semi-structured interviews and a problem situation followed by questions related to it. The results indicated that there is little knowledge from the teacher and students about the history of Africa. Considering the ethnic and racial issues, the most of students are able to identify discriminatory situations and judge them as bad.

Keyword: Pedagogical practices. Ethnic and racial issues. Teacher training.

\section{Introdução}

Ao priorizar a ideia de integração das minorias como um dos esteios da formação de um Estado Social, a presença cada mais afirmativa do Direito, de suas instituições e seus procedimentos na vida social a partir da vigência da Carta Magna de 1988, a importância da "raça" no debate político brasileiro é evidente se mencionarmos as várias mudanças legais ocorridas desde pelo menos final dos anos 1980, acompanhada de sua crescente inclusão na política partidária, nos meios de comunicação e pelo debate acadêmico.

Entre as medidas legais ocorridas, destacam-se o estabelecimento de disposições antidiscriminatórias na Constituição Federal de 1988, que transformou o racismo em crime inafiançável, protegeu a manifestação das culturas indígenas e afrobrasileiras, determinou a proteção legal aos documentos e locais dos antigos quilombos e garantiu o reconhecimento das terras ocupadas pelos quilombolas remanescentes; Lei $\mathbf{n}^{\circ} 10.558$, de 13/11/2002, que por meio de Medida Provisória ${ }^{0} 63$ estabeleceu a criação do Programa Diversidade na Universidade, no âmbito do Ministério da Educação, com a finalidade de implementar e avaliar estratégias para a promoção do acesso ao ensino superior de pessoas pertencentes a grupos socialmente desfavorecidos, especialmente dos afrodescendentes e dos indígenas brasileiros; Lei $\mathrm{n}^{\circ} 12.288$, de 20/07/2010, que criou o Estatuto da Igualdade Racial.

Essas medidas legais devem ser compreendidas como próprias de regimes democráticos. Neles, necessariamente a igualdade e a liberdade são os princípios estruturadores da sociedade, pelo qual o indivíduo é colocado como o principal ponto de 
referência. A coexistência desses dois ideais, no entanto, quando a igualdade levada ao extremo limita a liberdade e vice-versa, caracteriza grande parte dos principais conflitos passados e contemporâneos das democracias. Paralelamente, considera-se que para corrigir determinadas desigualdades (sejam elas de ordem social, racial/étnico, gênero) o Estado democrático deve intervir na sociedade para corrigir as suas desigualdades, pois é argumentado que a anterioridade fundacional do conceito de igualdade e uma consequente desinflação do conceito de liberdade ajudam na melhor compreensão da séria questão do pluralismo nas sociedades democráticas e também do próprio papel do cidadão nas democracias (RAWLS, 2000a, 2000b, 2003).

A Lei $\mathrm{n}^{\circ}$ 10.639/2001, de 9 de janeiro de 2003, estabeleceu a obrigatoriedade do ensino de história e cultura afro-brasileira e africana na educação básica, seguida pela publicação das "Diretrizes curriculares nacionais para a educação das relações étnico-raciais e para o ensino de história e cultura afro-brasileira e africana", cujo parecer e a resolução foram aprovados pelo Conselho Nacional de Educação (CNE), em março de 2004, e homologados pelo Ministério da Educação (MEC) em junho desse mesmo ano. A resolução foi resultado do Parecer CNE/CP3/2004, que teve como relatora a conselheira Petronilha Beatriz Gonçalves e Silva, da Câmara de Educação Superior do CNE (ABREU e MATTOS, 2008).

As noções de cultura e diversidade cultural, assim como de identidades e relações étnico-raciais, começaram, desde o final da década de 1990, a se fazer presentes nas normatizações aprovadas pelo Conselho Nacional de Educação (CNE) e homologadas pelo Ministério da Educação (MEC) com o objetivo de regular o exercício do ensino fundamental e médio, especialmente na área de história. Tais intervenções do Estado na educação ocorreram (e continuam a ocorrer) no quadro de transformações efetivadas, num conjunto alargado, em diferentes países de diversos continentes, a partir dos anos 1980, na questão da regulação das políticas e das ações públicas (BARROSO, 2005).

A Lei $\mathrm{n}^{0} 10.639 / 2003$ e as "Diretrizes curriculares nacionais para a educação das relações étnico-raciais e para o ensino de história e cultura afro-brasileira e africana" se deram em meio a uma espécie de "alforria curricular" (Araújo e Cardoso, 2003), num contexto educacional marcado pelas transformações advindas da promulgação da Lei de Diretrizes e Bases $n^{\circ}$ 9.394, de 1996, na qual estão presentes modificações educacionais importantes, como a flexibilização curricular, a consciência do valor da inclusão e da diversidade na educação, e a reafirmação da autonomia docente (PEREIRA, 2008).

A publicação dessa lei e das diretrizes também são tributárias de um movimento disperso e fragmentário que vinha ocorrendo nos governos estaduais e municipais no Brasil. Isso aconteceu com vistas à reparação de danos e para a ampliação dos canais de participação cidadã de populações sub-representadas, em defesa do seu direito à história e à cultura (PEREIRA, 2008). Como uma força irresistível, elas vieram à tona por meio de um complexo processo de democratização do país, acompanhadas de uma consciência de 
desigualdades históricas perpetradas contra populações e pessoas afro-descendentes. Esses eram sinais significativos de um novo lugar político e social conquistado pelos chamados movimentos negros antirracistas no processo político brasileiro e no campo educacional em especial (ABREU e MATTOS, 2008).

Os "Parâmetros Curriculares Nacionais" (PCNs), aprovados pelo MEC em 1996, introduziram no ensino o conteúdo de história africana, precedendo e preparando o terreno para as "Diretrizes". Dessa forma, considera-se que mesmo produzidos por governos de orientações políticas distintas, tal vinculação entre ambos revela como esses textos legais foram fruto principalmente do crescimento da força política dos movimentos negros na sociedade brasileira pós-redemocratização. Tudo isso aliado a um novo consenso no campo pedagógico em relação ao chamado "mito da democracia racial" no Brasil.

Aliado a isso, e de acordo com as Diretrizes Curriculares Nacionais (2004), ao iniciar este processo de políticas de reparações, propostas pelo governo, o primeiro passo a ser tomado é garantir o acesso, permanência e sucesso do negro na educação escolar. Para tanto, faz-se necessário que se formem programas de ações afirmativas - compreendidas como um "conjunto de ações políticas dirigidas à correção de desigualdades raciais e sociais" (p.12) que sejam compartilhados entre sistemas de ensino, estabelecimentos, cursos de formação de professores, comunidade, professores, pais e alunos.

Paralelamente, observa-se que sejam os PCNs ou as "Diretrizes", a sua escrita revela ambivalência, ambiguidade ou tensão, cuja resolução ficará a cargo das escolhas realizadas pelo educador em cada escola e sala de aula. Por isso, pergunta-se: o que sabem professores e alunos sobre a história da África? Como lidam sobre as questões étnico-raciais no contexto escolar? O interesse por estes temas foi proveniente da participação em uma Organização Não-Governamental (ONG) que luta pela inserção do negro em todos os âmbitos da sociedade, de forma a romper com o preconceito e proporcionar-lhe as mesmas oportunidades do branco. Ao mesmo tempo surgiu da vivência no contexto educacional, momento no qual se pôde conhecer a realidade do dia a dia e observar o trabalho docente, assim como as atitudes dos alunos a respeito da questão étnico-racial.

As questões referentes às relações étnico-raciais, bem como a presença do negro na escola e a divulgação da história de seu povo, ainda são assuntos muito polêmicos e silenciados, na maioria das vezes.

É comum o discurso de que a escola deve ser um espaço democrático, que preze pelo respeito à diversidade e que permita o acesso e a permanência de todos à educação, de forma igualitária. $\mathrm{O}$ que se percebe, porém, é que a heterogeneidade dos indivíduos e das culturas que se apresentam no ambiente escolar não é aceita e respeitada da maneira a qual a educação se propõe. Em decorrência disso, o exercício do racismo e de práticas discriminatórias inicia-se no seio das unidades escolares. Considerando que a escola é um 
ambiente heterogêneo, lugar onde pessoas de diversas origens étnico-raciais se encontram, é importante que os educadores estejam preparados para lidar com esta diversidade, de maneira a romper com o preconceito e impedir que situações discriminatórias e de racismo aconteçam no espaço escolar. Por que as pessoas discriminam umas às outras? Quais os valores que são explícitos ou implícitos nessas situações? Acreditamos que os valores perpassam todas as relações interpessoais, deste modo, o meio de convívio e instituições tais como a família, a escola, igreja, interferem nas condutas sociais ou antissociais de seus alunos (KOLLER e BERNARDES, 1997). Portanto, ressaltamos a necessidade de o professor rever suas práticas docentes e trabalhar objetivando a construção do respeito, da tolerância, da justiça e que, por fim, este trabalho resulte na formação de sujeitos mais autônomos e capazes de manter relações étnico-raciais harmoniosas. $O$ trabalho com essas relações é reconhecido como uma "reeducação das relações entre negros e brancos" (BRASIL, 2004, p.234).

Diante disso, observamos que as relações étnico-raciais são motivo de conflitos entre os alunos, devido à dificuldade em lidar com situações discriminatórias, por exemplo. Considerando que as crianças que frequentam o Ensino Fundamental I apresentam, na maioria das vezes, atitudes ainda heterônomas, ou seja, necessitam sempre da intervenção de um adulto, os valores construídos na sala de aula e transmitidos pela relação professoraluno e aluno-aluno podem ajudá-las ou não na resolução dos conflitos. Cabe ao professor promover um espaço de diálogo e discussão a respeito das questões étnico-raciais, para que estas não fiquem no imaginário dos alunos como situações exóticas e fora de contexto (GOMES, 2003).

Para Marchesi (2006), as experiências sociais do sujeito são constituintes de sua moralidade, portanto, a maneira como as relações étnico-raciais e os conflitos são abordados na escola está intimamente ligada às condutas que os alunos terão diante da resolução de um conflito. Os estereótipos atribuídos ao outro e situações de discriminação e racismo devem ser expostas e refletidas por alunos e professores, com vista a romper com a passividade das pessoas diante do problema e construir valores de respeito à diversidade e reconhecimento da igualdade de direitos de todas as pessoas.

\section{A pesquisa}

Reconhecendo a importância dos estudos sobre a História e cultura da África, bem como as questões étnico-raciais no contexto escolar, o presente trabalho estabeleceu como objetivos: a) compreender as representações do professor e alunos do Ensino Fundamental sobre as relações étnico-raciais no contexto escolar; b) verificar o conhecimento que o professor possui acerca da Lei $\mathrm{n}^{\circ}$ 10.369/2003 e dos conteúdos relativos à história e a cultura 
africana; c) analisar as representações do docente e dos discentes diante de uma situação de discriminação étnico-racial.

\section{Método}

Este estudo apresenta a abordagem de pesquisa qualitativa do tipo descritivo. Foram participantes uma professora e 21 alunos do quinto ano do Ensino Fundamental de uma cidade do interior do Estado de São Paulo. A sala de aula participante tinha treze meninos e oito meninas.

Como procedimento, utilizamos entrevistas semiestruturadas, individualmente, sendo que primeiramente realizávamos perguntas gerais sobre a temática e posteriormente apresentávamos uma situação-problema seguida de perguntas referentes à mesma. A situação-problema foi inspirada no documentário Olhos Azuis e descrita por Gomes (2005).

A entrevista com a professora envolveu seis questões abertas e uma situação-problema; com os alunos, as entrevistas envolveram cinco questões abertas e uma situação-problema, na qual foram apresentadas algumas figuras que ilustravam a situação. À medida que se contava a história (situação-problema) aos alunos, as figuras eram mostradas pela pesquisadora, sendo que cada figura correspondia a um trecho e o ilustrava para melhor entendimento. As questões respondidas pela professora eram diferentes das questões feitas aos alunos no que dizia respeito aos conhecimentos pedagógicos do professor. No entanto, o assunto tratado, assim como o foco da pesquisa e da análise, eram os mesmos. Tanto o questionário quanto a situação problema se referiam a questões sobre relações étnicoraciais no contexto escolar e sobre a forma como os conteúdos de História da África eram trabalhados e entendidos no Ensino Fundamental.

No que se refere às considerações éticas, todos os participantes receberam um termo de esclarecimento consentido em duas cópias, fornecido pelas pesquisadoras, no qual foram assegurados que seus nomes seriam mantidos em total anonimato por ocasião da publicação do trabalho, bem como as suas respostas. O projeto de pesquisa foi devidamente aprovado pelo comitê de ética sob o protocolo $\mathrm{n}^{0}$ 0202.0.142.000-09. As entrevistas foram transcritas e realizamos a análise de conteúdo das respostas e categorização das mesmas. 


\section{Discussão dos resultados}

Optamos por apresentar os resultados iniciando com a questão, suas categorias com um exemplo ilustrativo e a tabulação dos dados. Para a transcrição das entrevistas, os alunos foram identificados por números seguidos pela sigla do sexo ( $F$ - feminino ou $M$ masculino). Nota-se que um mesmo participante pode ter apresentado uma resposta que se enquadra em mais que uma categoria, assim os resultados do número de respostas variou conforme a questão realizada.

\section{A voz dos alunos}

Questão 1: Pense em seus colegas da sala. Você acha que eles são diferentes? No que?

Categoria 1 - Diferenças de condutas sociais: nesta categoria estão agrupadas as respostas que apresentam a identificação, por parte do aluno entrevistado, de diferenças em seus colegas que se remetem às condutas sociais, como: comportamento na sala de aula ou em momentos de brincadeira e questões de personalidade que influenciam nas relações entre eles. Um exemplo desta categoria é:

$14 F$ - Diferentes de que tipo?(Alguma coisa de diferente nos seus colegas? Eles são todos iguais?) Não. Um é calmo, outro é briguento, um é tímido, outro fala muito, outro gosta de ficar xingando, outro não.

Categoria 2 - Características Físicas: fazem parte desta categoria as respostas que destacam a percepção de diferenças físicas e de aparência em seus colegas. Um exemplo demonstra a representação que as crianças fizeram, como:

$13 M$ - Sim, um pouco. Tipo assim, a cor, o cabelo, a roupa.

Categoria 3 - Preferência: são as respostas que evidenciam as diferenças em relação a gostos e preferências pessoais. Encontramos um único participante que fez alusão a essas questões: 
$6 F$ - Eu acho, porque nem todo mundo são iguais. Porque alguns gostam de uma coisa, outros gostam de outra, porque alguns gostam de uma cor, outros gostam de outra.

Categoria 4 - Questão étnico-racial: nesta categoria estão agrupadas as respostas indicativas da negação de diferenças, porém evidenciam em suas justificativas a percepção de diferenças étnico-raciais. Nessa categoria apenas uma criança se reportou a isso, como está disposto a seguir:

$1 M$ - Eu acho que não, porque um é negro outro é branco, mas não pode ter racismo porque ele é preto e outro é branco, não pode ter. Um é branco, outro é preto, um é mulato, outro é um pouco branco e preto, é misturado.

Categoria 5 - Sem justificativa: Agrupam-se nesta categoria as respostas das crianças que afirmaram não existir diferenças entre os colegas, sem justificativa. Elas responderam apenas não.

Tabela 1: Diferenças entre os colegas

\begin{tabular}{l|c}
\hline \multicolumn{1}{c|}{ CATEGORIAS } & NÚMERO DE RESPOSTAS \\
\hline 1 - Diferenças de condutas sociais & 11 \\
2 - Características físicas & 6 \\
3 - Preferência & 1 \\
4 - Questão étnico-racial & 1 \\
5 - Sem justificativa & 4 \\
\hline \multicolumn{1}{c}{ TOTAL } & 23 \\
\hline
\end{tabular}

De acordo com o disposto na Tabela 1, observa-se que as crianças percebem que as pessoas se diferem umas das outras, no que diz respeito ao seu comportamento e atitudes e também quanto às características físicas, sendo referentes ao modo de se vestir e características referentes à cor da pele, tipo de cabelo etc. Apenas uma criança chama a atenção para o fato da questão étnica, destacando o fato de todos deverem ser considerados como iguais. 
Questão 2: Você já identificou alguma situação de discriminação? Qual?

Categoria 1: Discriminação racial: nesta categoria as respostas dos alunos evidenciaram situações de discriminação por questões raciais, principalmente, em relação à cor (Muniz: 2010). Temos como exemplo:

$1 M$ - Já, aqui na escola. Tipo, não ele não vai brincar porque ele é preto, é assim, é assim assado, ah ele não vai brincar, é fazer pouco caso.

Categoria 2: Condutas antissociais: encontram-se nesta categoria as respostas que trazem situações de condutas antissociais, ou seja, maneiras de agir que, de acordo com os entrevistados, não são adequadas. Elas ocasionaram situações de discriminação. Para exemplificar, temos a seguinte resposta:

$20 F$ - Não. (Nem na sala?) Na sala sim, porque a Gabriela arranhou o Caio. (Mas porque eles trataram diferente?) Porque o Caio tava conversando com a Vitória, aí a Gabriela chegou e arranhou ele.

Categoria 3 - Características físicas: respostas que identificam situações de discriminação devido a características físicas. Uma resposta que representa esta categoria é:

$18 M$ - Já. Os meninos lá na sala que usam óculos, os outros ficam chamando de "quatro olhos".

Categoria 4 - Discriminação social: respostas que apresentam discriminação em relação a questões sociais. Somente uma criança ressaltou esse fato, como veremos a seguir:

9F - Sim. Que tem uma menina que mora na favela, aí os outros ficam zuando ela.

Categoria 5 - Sem justificativa: respostas que revelam a não percepção de situações de discriminação ou a incompreensão do conceito da palavra discriminação, sem justificativa. As respostas foram apenas não. 
Tabela 2: Situação de discriminação

\begin{tabular}{l|c}
\hline \multicolumn{1}{c|}{ CATEGORIAS } & NÚMERO DE RESPOSTAS \\
\hline 1 - Discriminação racial & 3 \\
2 - Condutas antissociais & 3 \\
3 - Características físicas & 4 \\
4 - Discriminação social & 1 \\
5 - Sem justificativa & 10 \\
\hline \multicolumn{1}{c}{ TOTAL } & $\mathbf{2 1}$ \\
\hline
\end{tabular}

Verifica-se que a maior parte das crianças, praticamente a metade, não identifica uma situação de discriminação racial ou não compreendeu a pergunta e o conceito de discriminação, como podemos observar na Categoria 5 - Sem justificativa. Podemos inferir, também, que talvez essa parcela de alunos que não justificou suas respostas tenha adotado uma postura de não identificação da resposta que a pesquisadora buscava e esta foi uma tentativa de neutralidade.

Questão 3: Você já identificou alguma situação de discriminação racial no âmbito escolar? Se sim, aponte qual e como lidou com essa discriminação.

Categoria 1 - Abstenção: respostas que apresentam a falta de manifestação em uma situação de discriminação. Destacamos o seguinte exemplo:

$7 M$ - Eu já vi alguns xingamentos, pretão, essas coisas. (Como você lidou com essa situação?) Nunca me xingaram, então eu fiquei quieto, na minha.

Categoria 2 - Intervenção do adulto: a criança se manifestou e recorreu a outra pessoa para lidar com a situação. Uma única criança levantou esse tópico, como apresentado a seguir:

$18 M$ - Tem várias. Um monte de xingamentos, um monte de briga. (Explicação da pergunta) Tem, ficam chamando de macaco, de neguinho. (Como você lidou com isso?) Eu fico muito mal, porque tem a sala e eu sou negro, e eles ficam zuando, mas eu não ligo. (Eles falam isso para você?) Falam, mas eu não ligo. Eu sou negro mesmo. (E você não faz nada?) Só falo para a professora. (O que a professora faz?) Ela manda para a diretoria ou dá suspensão. 
Categoria 3 - Posicionamento: a criança se manifestou contra a situação e apresentou sua opinião. Temos um único exemplo para essa categoria:

6F - Não. (Explicação) Tem uns meninos que ficam chamando a Adriele de "cabelo de Bombril". (Por que ela é negra?) É. Eu falo pra eles, cada um tem seu jeito diferente. Por exemplo: um menino é branco e tem cabelo liso, outro é negro e tem cabelo diferente. Aí eles falam que não.

Categoria 4 - Negação: fazem parte desta categoria as respostas das crianças que afirmaram nunca terem presenciado uma situação de discriminação racial. Desse modo, as respostas foram apenas não.

Tabela 3: Situação de discriminação racial

\begin{tabular}{l|c}
\hline \multicolumn{1}{c|}{ CATEGORIAS } & NÚMERO DE RESPOSTAS \\
\hline 1 - Abstenção & 7 \\
2 - Intervenção do adulto & 1 \\
3 - Posicionamento & 1 \\
4 - Negação & 12 \\
\hline \multicolumn{1}{c|}{ TOTAL } & $\mathbf{2 1}$ \\
\hline
\end{tabular}

A categoria que obteve o maior número de respostas foi a Categoria 4 - Negação, deste modo, essas crianças afirmaram que nunca presenciaram uma situação de discriminação racial, porém, é possível imaginar que estas crianças tenham dado esta resposta para fugir de uma justificativa. Em segundo lugar, temos a Categoria 1 - Abstenção, na qual as respostas retrataram situações de discriminação racial, porém, as crianças não tomaram nenhuma atitude frente à situação, apenas se calaram. $\mathrm{E}$ as outras duas categorias tiveram somente uma resposta. Percebe-se, portanto, que entre todos os entrevistados apenas duas crianças se posicionaram de alguma forma ao presenciar uma situação de discriminação racial.

Questão 4: O que você sabe sobre a História da África? O que seu professor(a) fala sobre isso? Você se lembra de mais alguma coisa? 
Categoria 1 - Relação com os portugueses e/ou escravidão: respostas em que os alunos apresentaram uma relação entre a História da África e os conteúdos estudados sobre os portugueses no Brasil e o período da escravidão. Temos como exemplo:

$11 M$ - Eu só sei que tinha muitos negros. Só sei que chegou os portugueses e começaram a tratar eles como escravos.

Categoria 2 - Questões sociais: respostas que apresentaram uma associação da África com pobreza e desigualdade social. Destacamos o seguinte exemplo sobre a questão:

$17 M$ - Lá as pessoas passam fome, muitas não têm água pra beber. (O que sua professora fala sobre isso?) Não sei.

Categoria 3 - Desconhecimento: as crianças afirmaram não conhecer nada sobre a história da África ou não se recordaram de a professora ter trabalhado esse conteúdo. Apresentamos uma resposta que pode exemplificar:

$16 F$ - Não sei de nada, porque não estudei sobre isso. (O que sua professora fala sobre isso?) Que eu me lembre não falou nada.

Tabela 4: Conhecimento sobre a história da África

\begin{tabular}{|c|c|}
\hline CATEGORIAS & NÚMERO DE RESPOSTAS \\
\hline 1 - Relação com os portugueses & 8 \\
\hline 2 - Questões sociais & 8 \\
\hline 3 - Nenhum conhecimento & 5 \\
\hline TOTAL & 21 \\
\hline
\end{tabular}

A Tabela 4 mostra que as respostas foram bem divididas nessa pergunta e que o mesmo número de crianças apresenta conhecimento em relação ao período portugueses/escravidão e questões sociais relativas à África. Um número menor de respostas é demonstrativo da falta de conhecimento que algumas crianças possuem sobre a história da África.

Questão 5: Qual a relação da África com o Brasil? 
Categoria 1 - Questão de cor: apresentou-se a ideia de que na África todos ou a maioria é de negros e no Brasil a população, em sua maioria, é branca.

9F - Que no Brasil têm negros, mas é mais brancos e na África mais negros.

Categoria 2 - Questão social: destacam aspectos de desigualdade social, dificuldades financeiras, principalmente em relação à comida. Destacamos uma resposta para exemplificar:

6F - [...] Aqui a gente tem as coisas pra comprar, tem bastante comida e lá eles não têm quase nada, não têm nada pra eles comprarem, e eles vivem num lugar sem nada.

Categoria 3 - Questão cultural: os alunos perceberam diferenças culturais em relação aos dois países. Apresentamos um exemplo:

$16 F$ - Relação que eles falam, às vezes, uma língua que não é a nossa [...].

Categoria 4 - Sem justificativa: fazem parte desta categoria as respostas dos alunos que demonstraram não estabelecer nenhuma relação entre Brasil e África.

$8 M$ - Nenhuma.

Tabela 5: Relação entre África e Brasil

\begin{tabular}{l|c}
\hline \multicolumn{1}{c|}{ CATEGORIAS } & NÚMERO DE RESPOSTAS \\
\hline 1 - Questão de cor & 6 \\
2 - Questão social & 4 \\
3 - Questão cultural & 2 \\
4 - Sem justificativa & 12 \\
\hline \multicolumn{1}{c}{ TOTAL } & $\mathbf{2 4}$ \\
\hline
\end{tabular}

A categoria que obteve o maior número de respostas foi a Categoria 4 - Sem justificativa. Isso ressalta a falta de reconhecimento das crianças sobre a influência dos 
negros na cultura e sociedade brasileira, pois, se não fazem relação entre a África e o Brasil, tampouco percebem a relevância do elo entre os dois continentes (africano e americano) na nossa história. A Categoria 1 - Questão de cor ficou em segundo lugar e contém as respostas daqueles que destacaram a cor da pele dos africanos e brasileiros como a relação existente entre os dois países. Esse fato revela que quando é feita uma relação entre a África e o Brasil, a primeira alusão feita pelas crianças foi referente aos negros, o que comprova a ligação que fazem entre África - negros - Brasil - escravidão.

\section{Situação problema}

A situação destacada a seguir foi lida pela pesquisadora aos alunos, e no decorrer da leitura as figuras ilustrativas foram apresentadas. Após a leitura, os alunos foram questionados a respeito de seu entendimento sobre a mesma e a pesquisadora fez alguns esclarecimentos, quando necessário. Verificou-se que a utilização das figuras tornou a situação mais compreensível aos alunos. ${ }^{6}$

Tudo começou com uma professora que lecionava no interior dos EUA. Um dia, ela se viu questionada pelos alunos sobre os motivos que levaram ao assassinato do líder negro Martin Luther King, em 1968, nos EUA. A partir dessa curiosidade das crianças, a professora se viu diante de um desafio: como explicar uma questão tão complexa para seus alunos? Que recursos ela poderia usar para tornar o assunto compreensível para aquelas crianças? Ela se deu conta de que não havia recursos didáticos para explicar aos alunos o que era realmente o racismo. Assim, a professora concluiu que só se as pessoas pudessem se colocar no lugar daqueles que eram discriminados racialmente é que elas poderiam compreender o que era racismo. Então, ela teve uma ideia: realizou com os seus alunos uma dinâmica de grupo em que, durante um dia letivo inteiro, as crianças que tivessem olhos azuis passariam por uma situação de discriminação. Elas deveriam ser rejeitadas pelas outras devido à cor de seus olhos. Ter olhos azuis seria, a partir daquele momento, um atributo merecedor de desprezo. A escolha da cor dos olhos, uma característica do fenótipo (assim como a cor da pele), foi a forma mais próxima de fazer as crianças se aproximarem do drama dos negros que sofrem a discriminação racial devido a fatores históricos, culturais e também raciais. Nesse caso, a cor da pele, o tipo de cabelo, o formato dos lábios, entre outras características que remetem à herança africana, são vistos pelo racista como marca de inferioridade. A dinâmica foi explicada e negociada previamente com as crianças, que aceitaram a proposta. Então, durante esse dia, as crianças de olhos azuis foram rejeitadas por seus colegas que não conversaram direito com elas, não as respeitavam, não bebiam

6 Todas as figuras utilizadas foram especialmente confeccionadas para a pesquisa pelo desenhista Caio Sievers Sperandio. 
no mesmo bebedouro, em suma, as discriminavam. A professora acompanhou toda a experiência e fotografou as crianças antes e depois do trabalho. Ao terminar a aula, a classe inteira se reuniu para discutir o que havia acontecido. Os alunos e as alunas falaram sobre o que sentiram, principalmente, os de olhos azuis. Os sentimentos giravam em torno de sensações como: impotência, raiva, vontade de vingança, tristeza, ressentimento, inferioridade e incapacidade. A professora discutiu com a turma sobre o que eles tinham achado do comportamento adotado pelos alunos que não tinham olhos azuis. Ele fazia sentido? Unanimemente, a classe disse que não. Concluíram, a partir daquela experiência, que não se deve julgar ou maltratar as pessoas simplesmente porque nasceram com a cor dos olhos diferente umas das outras. A cor dos olhos em nada interfere no caráter, na personalidade e na capacidade das pessoas e nem deveria ser um critério para que alguns grupos humanos fossem tratados de maneira desigual em relação aos outros. Após uma longa conversa com os alunos, analisando cada fato acontecido durante aquele dia letivo, a professora pôde relacionar a dinâmica realizada com a questão racial. Explicou para a classe o sistema escravista, o racismo e a situação dos negros norte-americanos. Explicou, também, a atuação de Martin Luther King na luta pelos direitos civis, pela superação do racismo e o tanto que ele e outros ativistas negros incomodavam a ordem racista que imperava na sociedade norte-americana da época. Assim, ela também pôde explicar por que esse grande líder negro havia sido assassinado (GOMES, 2005, p.149).

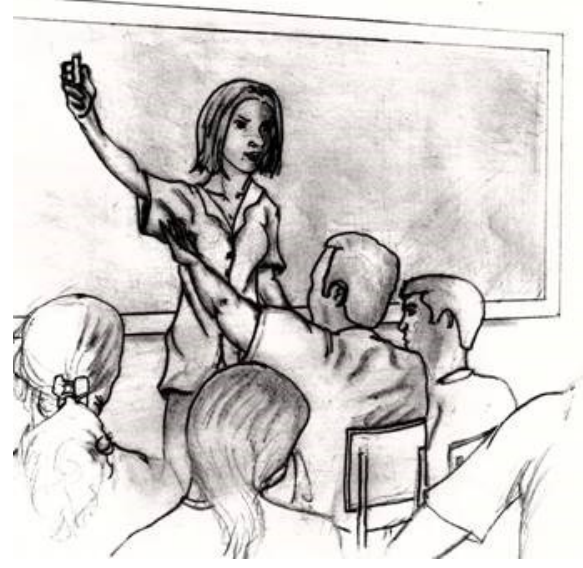

Figura 1

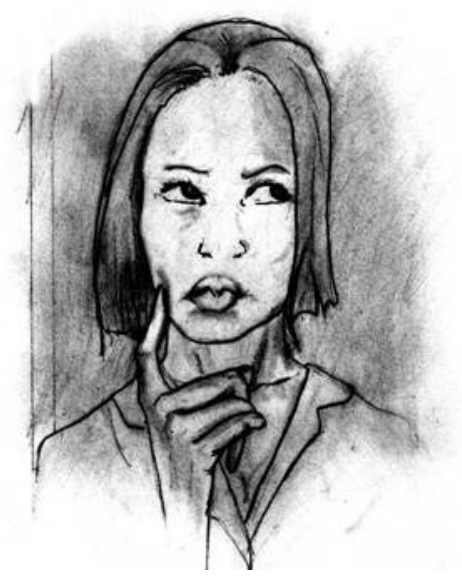

Figura 2 


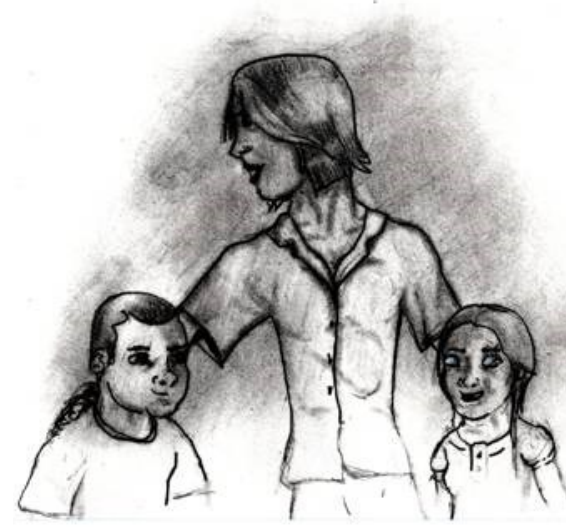

Figura 3

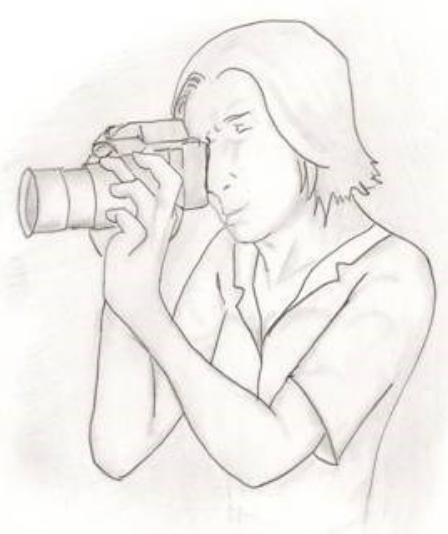

Figura 5

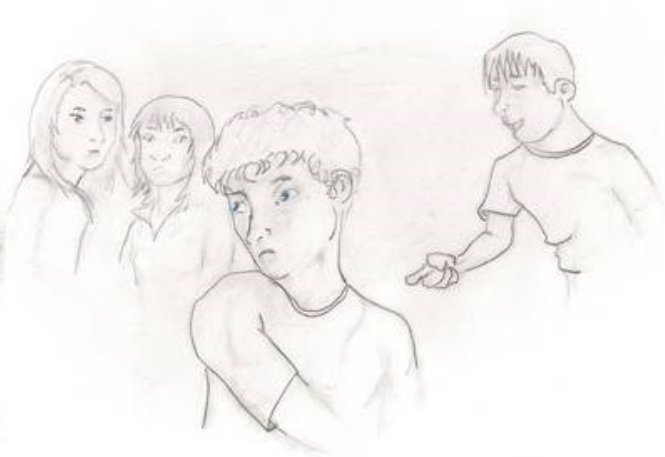

Figura 4

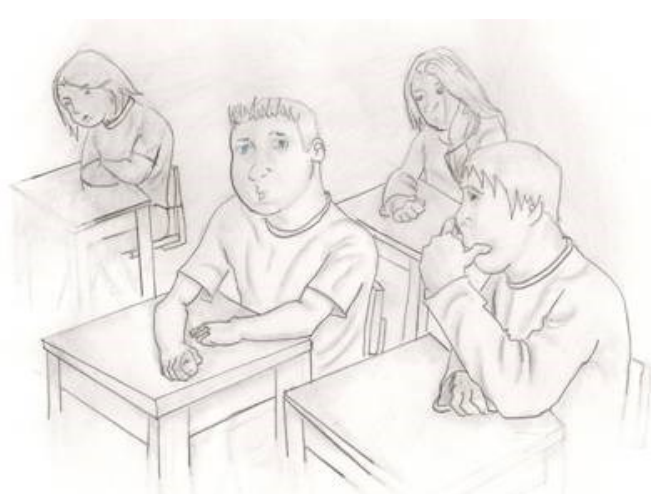

Figura 6 


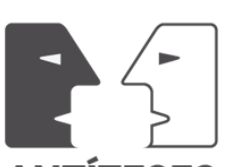

ANTÍTESES

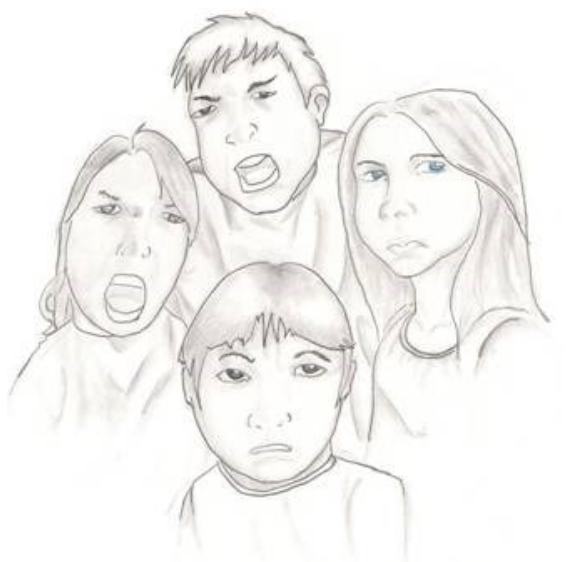

Figura 7

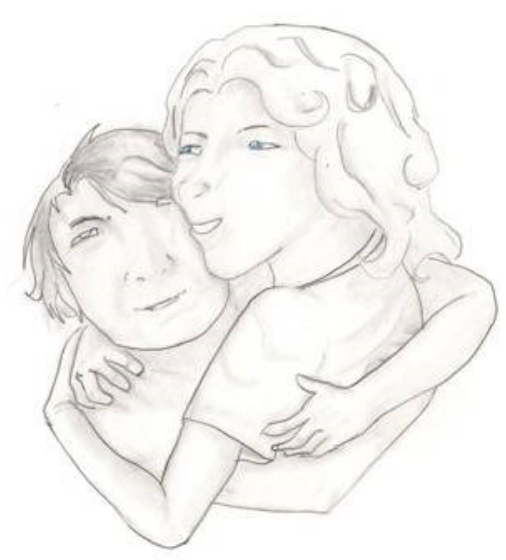

Figura 8

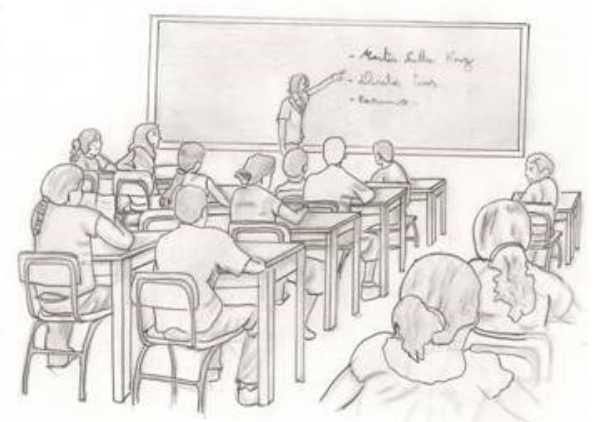

Figura 9

Questão 1: O que você acha da atitude dessa professora?

\section{Categoria 1 - Concorda com a atitude}

$1 M$ - Certa, por causa que maltratavam o Martin, aí ela fez isso pra ver que não podia fazer nem com eles e pra, como é que fala? E pra ver que não pode tratar mal ninguém, é só brincar com todo mundo e não tem essa de racismo. Ah ele é negro então não vai brincar, ele tem olhos azuis então não vai brincar, isso não pode.

\section{Categoria 2 - Discorda da atitude}


$15 F$ - Não gostei. Só porque os outros têm olhos azuis não quer dizer que eles não possam beber no mesmo bebedouro que os outros e fazer as mesmas coisa.

Tabela 6: Atitude da professora

\begin{tabular}{c|c}
\hline \multicolumn{1}{c|}{ CATEGORIAS } & NÚMERO DE RESPOSTAS \\
\hline 1 - Concorda com a atitude & 14 \\
2 - Discorda da atitude & 7 \\
\hline TOTAL & 21 \\
\hline
\end{tabular}

Verificamos que as crianças discordaram da atitude da professora por não perceberem os objetivos da mesma com a dinâmica e se prenderam apenas à situação de discriminação apresentada. Um fato interessante na análise das respostas é que embora as crianças não compreendessem a intenção da professora, todas se opuseram à situação de discriminação e explicitaram seus julgamentos em relação a tal situação.

Questão 2: O que você acha que essa professora tentou ensinar para seus alunos?

Categoria 1 - Sobre racismo e/ou discriminação: nesta categoria estão as respostas que fazem alusão aos conceitos de racismo e discriminação como ensinamentos da professora. $O$ exemplo a seguir pode demonstrar:

$2 F$ - Que se é branco, preto, não importa. O que importa é o caráter da pessoa.

Categoria 2 - Igualdade: esta categoria compreende as respostas que destacaram que pregar a igualdade entre as pessoas era o objetivo da professora ao realizar a dinâmica.

6F - Que não importa a cor dos olhos nem a cor da pele, que todo mundo é igual. 
Categoria 3 - Valorização e/ou respeito: as respostas agrupadas nesta categoria levantaram a valorização e o respeito como princípios a serem ensinados pela professora. Tivemos apenas um exemplo nessa categoria, como está disposto a seguir:

$14 F$ - Ela explicou a morte do Martin Luther King e ela ensinou que cada pessoa tem seu valor, que a pessoa de olho azul tem seu valor, a pessoa negra tem seu valor, a pessoa que é isso tem seu valor, a pessoa que é aquilo tem seu valor.

Categoria 4 - Incompreensão dos fatos: algumas crianças não compreenderam o objetivo da dinâmica, apesar das explicações da pesquisadora. A seguir temos um exemplo dessa resposta:

$4 M$ - Que ela queria que todo mundo tivesse o olho igual, mas não é todo mundo que tem. Um tinha o olho azul e o outro não.

Tabela 7: Ensinamentos da professora

\begin{tabular}{l|c}
\multicolumn{1}{c|}{ CATEGORIAS } & NÚMERO DE RESPOSTAS \\
\hline 1 - Racismo e/ou discriminação & 13 \\
2 - Igualdade & 3 \\
3 - Valorização e/ou respeito & 1 \\
4 - Incompreensão dos fatos & 5 \\
\hline TOTAL & 22 \\
\hline
\end{tabular}

Questão 3: Imagine que você estava nessa sala e que tinha olhos azuis. Como você se sentiria?

Categoria 1 - Positiva: compõem esta categoria as respostas das crianças que declararam que se sentiriam bem na situação descrita. Temos apenas um exemplo:

$5 M$ - Me sentiria bonito. (Mas as crianças que tinham olhos azuis foram tratadas diferentes naquela sala, elas foram rejeitadas nesse dia). Ah não sei. 
Categoria 2 - Rejeição: as respostas desta categoria afirmam que essas crianças ficariam tristes por se sentirem desprezadas pelos outros e por não terem companhia. Segue um exemplo:

$6 F$ - Eu me sentiria triste por ser rejeitada pelos outros.

Categoria 3 - Discriminação: as respostas que fazem parte desta categoria sugeriram que a situação era discriminatória e os sentimentos giraram em torno de humilhação e tristeza. Segue um exemplo:

$2 F$ - Eu ia me sentir mal. Porque os outros que são discriminados, eles também se sentem mal, quem é discriminado se sente mal.

Categoria 4 - Outros: nesta categoria agrupam-se as respostas que demonstram que as crianças não gostariam de passar por aquela situação por motivos diversos. Destacamos um exemplo:

$19 M$ - Mal. Sentia mal e não gostava.

Tabela 8: Como as crianças se sentiriam

\begin{tabular}{|c|c|}
\hline CATEGORIAS & NÚMERO DE RESPOSTAS \\
\hline 1 - Positiva & 1 \\
\hline 2 - Rejeição & 13 \\
\hline 3 - Discriminação & 3 \\
\hline 4 - Outros & 4 \\
\hline TOTAL & 21 \\
\hline
\end{tabular}

Verifica-se que a Categoria 2 - Rejeição apresentou o maior número de respostas, sendo assim, essas crianças demonstraram que ao imaginarem-se em uma situação de discriminação o que mais as afetaria seria o fato de se sentirem sozinhas e sem amigos. Em segundo lugar, encontra-se a Categoria 4 - Outros, em que se agrupam as respostas de crianças que afirmaram que não gostariam de passar por uma situação de discriminação e se sentiriam mal e tristes. Outras crianças apontaram para a discriminação, como se observa 
na Categoria 3. Nela, as crianças demonstraram compreender o significado do conceito de discriminação e afirmaram que uma situação assim provocaria sentimentos de humilhação, tristeza e ofensa.

\section{A voz da professora}

Questão 1: O que você entende por diversidade no contexto escolar?

$P$ - Eu acho que existe toda uma população que é diferente, que é diversa, por vários motivos, sejam étnicos, ou sociais, culturais, enfim.

Questão 2: Você já identificou alguma situação de discriminação racial no âmbito escolar? Se sim, aponte qual e como lidou com esta discriminação.

$P$ - Sim. Já verifiquei. (Como você lidou?) Resgatando valores, a nível de tolerância, de respeito, de cooperação. (Você presenciou isso entre os alunos?) Entre os alunos e já também entre profissionais. $\hat{E}$ evidente que entre profissionais eu não fiz esse resgate, trabalhando com valores, mas eu mantive uma postura minha, me distanciando da situação e agindo de forma diferente.

Questão 3: O que você sabe sobre a História da África?

$P$ - Eu conheço o que eu leio nos livros e o que acabo ouvindo na televisão, em filmes. Mas, eu acho que é muito pouco, é o básico.

Questão 4: Quais são os conteúdos que você trabalha sobre a História da África? Como estes estão dispostos no currículo escolar?

$P$ - Dentro do conteúdo do $5^{\circ}$ ano o que pega bastante é quando a gente está trabalhando a história do Brasil, que vem desde os índios, depois os escravos. Quando a gente está discutindo essa questão da escravidão mesmo, quando chega nesse ponto da história do Brasil é que a gente conversa mais sobre o assunto, ou quando tem alguma outra atividade que acaba acontecendo durante $o$ ano, que a gente entra no assunto também. No meu planejamento tem a história do Brasil e foi pedido também que a gente encaixasse essa lei pra ser trabalhada durante $o$ ano. 
Questão 5: O que você conhece sobre a lei 10.639/03?

$P$ - Já foi lida em uma de nossas reuniões. (E o que foi dito? Vocês chegaram a discutir como trabalhar o que essa lei propôs?) Não chegamos a conversar especificamente, como vamos dar, qual o tratamento que vamos dar a essa questão. Sim, claro que a equipe gestora nos cobra como está sendo trabalhada essa questão, porque ela é contemplada quando a gente faz a avaliação do Projeto Pedagógico e está lá: Como é que estamos trabalhando? Agora existem professores que são afrodescendentes e que trabalham mais especificamente com projetos, talvez seja esse projeto com a professora de Artes.

Questão 6: O que você entende por trabalhar as relações étnico-raciais no contexto escolar?

$P$ - Eu acho que o trabalho tem que acontecer no dia a dia. Não adianta você pegar uma semana, um mês, para trabalhar aquilo e depois esquecer. Então você tem que bater naquilo diariamente, conforme vão aparecendo os assuntos. Não que não resolva o trabalho, como trabalhar a História da África num mês é lógico que vai resolver, porque eles vão adquirir mais conhecimento. Mas, eu acho que tem que ser pontual mesmo e conforme vai aparecendo, voltando no assunto e discutindo.

\section{Situação Problema}

A professora leu a história e não houve a utilização das figuras. Em seguida fez-se o seguinte questionamento a elas:

Questão 1: O que você acha da atitude dessa professora?

$P$ - Eu, como professora, acho que cada um dentro da sua sala, com os seus alunos, você deve achar o que dê mais resultado para você. Uma classe não é igual à outra, tem muitas diferenças e eu acho que foi uma atitude boa, foi uma maneira que ela encontrou de atingir os objetivos dela.

Questão 2: Você utilizaria esse procedimento? Por quê? 
$P$ - Não. Eu acho que não porque como os meus alunos são pequenos, e como eu já disse anteriormente, que eles não têm isso, a não ser que seja muito influenciado por um adulto, eu acho que despertaria para outras questões, não só para as questões raciais, como para outras diferenças também.

Questão 3: Como você acha que os alunos que tinham olhos azuis se sentiram?

$P$ - Eu questiono. Se talvez eles estivessem na África, porque existe aquele conhecimento de que eles não estão na África, que eles não são os diferentes, eles estão nos Estados Unidos. Mesmo que naquele momento eles fossem discriminados, a realidade não era essa. (Você acha que eles não se colocaram totalmente no lugar dos outros?) Não, eu acho que foi uma coisa emocional de momento. Eu não acredito nessas coisas de muito impacto, as coisas não acontecem, as coisas não mudam assim de repente. É como aquelas coisas da solidariedade, passou, não modificou nada, vou continuar agindo da mesma forma. Eu não acredito nessas coisas de muito impacto.

Questão 4: E os seus alunos? O que sentiriam se você aplicasse esse procedimento?

$P-E$ isso que eu falei mesmo. Eu acho que até eles sentiriam essa rejeição, mas não a ponto de poder comparar o que sentem os outros, principalmente, eles sabendo da situação. Se eles não soubessem pode ser que o negócio fosse diferente, que eles fossem sentir mais e depois conseguissem até uma reflexão mais profunda disso, mas sabendo do que aconteceu, eles já estavam preparados.

\section{Considerações Finais}

Embora tenhamos trabalhado com um estudo de caso e contado apenas com uma parcela muito pequena de uma rede escolar, a presente pesquisa traz contribuições para reflexões sobre uma temática que vem sendo discutida no âmbito escolar de forma mais incisiva desde 2003, a partir da lei 10.639.

Pensou-se no Ensino Fundamental como ponto de partida porque o seu currículo escolar implícita ou explicitamente pode remeter a preconceitos, intolerância e discriminações. Para tanto se faz necessário que toda a equipe escolar, principalmente os docentes, se conscientize da importância do respeito à diversidade e de discussões das questões étnico-raciais em sala de aula, proporcionando, assim, um ambiente favorável a 
construção de identidade do aluno e reconhecimento da influência da cultura africana na sociedade brasileira.

No entanto, a abertura para o conhecimento a respeito da cultura africana será possível somente se a escola deixar de lado a visão etnocêntrica - idéia de que há uma cultura superior a todas as outras culturas - reproduzida nos conteúdos escolares, e incluir outros que se referem à cultura afro-brasileira, mas que vão além do trabalho com datas folclóricas ou comemorativas, para que se construa um respeito às diferenças.

Muitas são as sugestões dadas por Rocha e Trindade (2006) para que se lide com estas questões em sala de aula, sendo que, a recuperação de identidade e desconstrução de estereótipos preconceituosos atribuídos ao grupo negro são fatores extremamente relevantes no processo de implantação de uma educação contra o racismo.

Por meio dos dados referentes ao primeiro objetivo desta pesquisa - Compreender as representações de professores e alunos do Ensino Fundamental sobre as relações étnicoraciais no contexto escolar - verificamos que as crianças identificam diferenças étnicoraciais em seus colegas, pois, muitas vezes, se referiram às diferenças da cor de pele das pessoas, tipo de cabelo e aparência em geral. Observamos, também, que as crianças se envolvem e presenciam conflitos relacionados às situações discriminatórias, como atribuição de apelido ao outro, principalmente em relação ao seu pertencimento étnicoracial. Porém, percebemos que existe uma grande dificuldade deles ao lidar com essas situações, e, devido a este fato, as crianças se silenciam e não se manifestam frente a uma situação de discriminação racial, na maioria das vezes.

Quando questionamos a professora a respeito do trabalho que realiza em relação às relações étnico-raciais, notamos que ela não apresentou nenhum procedimento claro para trabalhar com estas relações. Frente a uma situação de discriminação, disse que faz um resgate de valores para lidar com a situação ou se abstém de um posicionamento ativo, quando a situação envolve adultos.

Nosso segundo objetivo foi: Verificar o conhecimento que os professores possuem acerca da Lei $n^{\circ}$ 10.639/2003 e dos conteúdos relativos à História e a cultura africana. Nesse sentido, observamos que a professora conhece os termos da lei, pois a mesma já foi lida e comentada pela equipe gestora, mas que não existe um planejamento elaborado especificamente para trabalhar com a temática e que cumpra exatamente com o que está disposto na lei. Observa-se que há uma exigência da equipe gestora para que se trabalhe com essas questões, mas, pelo o que percebemos, não há um acompanhamento e uma orientação direta para o desenvolvimento desse trabalho.

No que diz respeito aos conteúdos referentes à história e cultura africana, a professora afirmou que possuía pouco conhecimento e se mostrou insegura para ensiná-los, devido à 
falta de formação. Constatamos que os conteúdos trabalhados, bem como a atenção dada a essa questão, ainda são insuficientes. Os professores necessitam formação e orientação esclarecida sobre práticas e estratégias que atendam ao que está previsto na lei e busquem romper com o racismo e as situações discriminatórias presentes em seu cotidiano escolar, assim como os auxiliem a lidar com estas situações.

Nas respostas dos alunos, os conteúdos ou conhecimentos que foram salientados se referiram somente ao período da escravidão, à relação entre portugueses e africanos e a algumas questões sociais da África, com enfoque na pobreza e desigualdade social. Esse fato compromete a construção de conhecimentos sobre a temática por parte do aluno e a capacidade deles de compreenderem o contexto da diversidade étnico-racial de nosso país.

Como último objetivo, procuramos: Analisar as representações sociais dos docentes e dos alunos diante de uma situação de discriminação étnico-racial. Diante dessa situação problema tivemos diferentes pontos de vista, tanto por parte da professora quanto dos alunos. A professora julgou a atitude da professora como boa, mas não necessariamente a repetiria, pois acreditava que houve um momento propício para a realização da dinâmica. Foi possível observar que a professora avaliou a situação com certo distanciamento, vendo-a como fictícia, portanto não a julgou como uma estratégia positiva que servisse como exemplo para outros educadores e que devesse ser reproduzida. Outro motivo, talvez, para que a professora não visse o procedimento como exemplo a ser seguido, é o fato de ela acreditar que os alunos não mudariam totalmente sua conduta, pois a situação não permitiu que eles realmente se colocassem no lugar dos negros - de acordo com ela.

Os alunos, em sua maioria, consideraram boa a atitude da professora e perceberam os objetivos desta com a dinâmica, pois ressaltaram em suas respostas conceitos significativos, tais como: racismo, discriminação, respeito, valorização e igualdade. Diferente do que a professora imaginou, eles conseguiram se colocar no lugar do outro, deste modo, afirmaram que se sentiriam mal diante da situação e apresentaram sentimentos que giraram em torno de: rejeição, discriminação, tristeza, humilhação, entre outros. A partir das questões e da situação problema, observamos que a maioria dos alunos é capaz de identificar situações discriminatórias e julgá-las como ruins, bem como atitudes que não devam se repetir.

Diante do exposto, podemos sugerir algumas indicações de um caminho que leve os docentes a iniciar um processo de verdadeira inclusão dessa temática no currículo escolar. Entendemos que o primeiro passo a ser dado deve partir das instituições de ensino superior, ao inserir na grade curricular dos cursos de licenciatura conteúdos da história da África, de modo a possibilitar um futuro trabalho dos professores nas escolas. Seria necessária, também, uma formação continuada aos professores já atuantes, para que se reverta esse quadro. 
A viabilidade desse trabalho depende, ainda, do apoio pedagógico dos gestores por meio da disponibilização de material didático e bibliográfico aos professores, momentos de discussão e reflexão sobre as questões étnico-raciais. Cabe aos professores aproveitar e ressaltar as diferenças entre os alunos positivamente, com o intuito de estabelecer relações interpessoais de respeito, aceitação e harmonia na sala de aula.

Tratando-se especificamente dos conteúdos programáticos, compreendemos que estes devem abordar a cultura africana em diversos aspectos, por meio da linguagem, música, literatura e arte. Destacamos esses aspectos, pois segundo as orientações pedagógicas do MEC, recomenda-se que o trabalho com essa temática aconteça por meio da interdisciplinaridade, de modo significativo aos alunos e condizente com seu contexto.

A presente pesquisa buscou indicar que o trabalho com as relações étnico-raciais e com a história da África não atende, da melhor maneira, ao que está previsto na lei, de modo que seja preciso rever práticas e pensar em novas estratégias que garantam ao povo negro ter sua história e cultura reconhecidas e valorizadas dentro da escola. Afinal, essa instituição é uma considerável formadora de opiniões, condutas e participante ativa da construção da sociedade em que vivemos.

Por sua vez, nota-se que há tempos que os negros no Brasil estão reivindicando os seus direitos, sobretudo como reparação social do seu passado escravista. Em resposta, tardia, o Estado brasileiro, com a sua última Constituição de 1988, valida e institucionaliza que membros de uma determinada cultura possam usar direitos políticos de cunho individualista, no exercício de sua autonomia pública, para proteger a identidade de suas próprias culturas. Concomitantemente, a sobrevalorização da cultura, cuja ênfase recai em considerar a esfera cultural como a moldura principal ou exclusivista para o crescimento do homem, está permitindo uma tendência teórica que vem se difundido cada vez mais no sentido de efetuar as análises sociais e históricas sobre contextos particulares, em oposição às grandes totalizações do passado. Como reflexo imediato deste particularismo cultural e normativo, há uma atuação para que a educação formal seja diferente e, paradoxalmente, sob a forma de direitos coletivos. Considera-se que há de se estabelecer uma distinção entre cultura política e cultura no sentido etnográfico, e criticar o approch particularista e defender o universalismo, pois as públicas políticas afirmativas sub-repticiamente introduzem um controle pelo Estado sobre os agentes sociais que buscam ter o direito de viver e educar os seus filhos no contexto cultural em que eles próprios se reconhecem como pessoas e encontram a sua identidade.

Já quanto às relações entre o Estado, a Sociedade e o Indivíduo, consideramos que se deve buscar compreender a ação do Estado democrático-liberal brasileiro sobre a questão racial, por meio da educação, os seguintes aspectos que se destacam: a) mesmo sofrendo as influências de medidas sociais ocorridas em outros países - especialmente as realizadas nos Estados Unidos, as denominadas "ações afirmativas" -, a questão racial ainda é um tema a ser 
resolvido a partir do que Nancy Fraser (2009) denominou de "enquadramento KeynesianoWestfaliano", pelo qual, em regra, as discussões acerca da justiça concernentes às relações entre os cidadãos deveriam "submeter-se ao debate dentro dos públicos nacionais e contemplar reparações pelos Estados nacionais"; b) a anterioridade fundacional do conceito de igualdade e uma consequente desinflação do conceito de liberdade significam que os conceitos de liberdade e de igualdade estão definidos a partir da estrutura de poder, cuja liberdade é uma liberdade externa pela qual temos o poder de realizar também aquilo que os outros indivíduos fazem, porque anteriormente considera-se que um indivíduo é igual ao outro indivíduo, e os extremos da liberdade individual são coibidos e sofre as sanções de um poder que é externo ao indivíduo, é mais forte do que ele e tem força de lei através do "enquadramento Keynesiano-Westfaliano"; c) a anterioridade fundacional do conceito de igualdade e uma consequente desinflação do conceito de liberdade significam que o indivíduo é considerado como um ser empírico que não pode ser modificado pela educação, ou seja, o indivíduo é um ser acabado que não se altera por nenhuma ação interna ou externa a ele. Ou seja, há paradoxos nessa intervenção do Estado democrático-liberal brasileiro sobre a questão racial por meio da educação.

\section{Referências}

ABREU, M.; MATTOS, H. Em torno das "Diretrizes curriculares nacionais para a educação das relações étnico-raciais e para o ensino de história e cultura afro-brasileira e africana": uma conversa com historiadores. Estudos Históricos, v.21, n.41, p. 5-20, 2008,

ARAÚJO, Joel J.; \& CARDOSO, Patrycia de Resende. 2003. Alforria curricular através da Lei 10.639. Revista Espaço Acadêmico, $\mathrm{n}^{\circ}$ n.30, nov. nov. 2003. Disponível em www.espacoacademico.com.br/030/30 caraujo.htm. Acesso em 26 de setembro de 2011.

BARROSO, João. O Estado, a educação e a regulação das políticas públicas. Educação e Sociedade, v.26, n.92, p.725-751, 2005.

BRASIL. Lei de Diretrizes e Bases da Educação Nacional. Lei número 9394, 20 de dezembro de 1996.

BRASIL. Lei no. 10.639 de 09 de janeiro de 2003. Inclui a obrigatoriedade da temática "História e Cultura Afro-Brasileira" no currículo oficial da rede de ensino. Diário Oficial da União, Brasília, 2003.

BRASIL. Ministério da Educação; Secretaria de Educação Continuada, Alfabetização e Diversidade; Secretaria Especial de Políticas Públicas de Promoção da Igualdade Racial. 
Diretrizes Curriculares Nacionais para a Educação das Relações Étnico-Raciais e para o Ensino de História e Cultura Afro-brasileira e Africana. Brasília: MEC/SEPPIR, 2004.

FRASER, Nancy, Reenquadrando a justiça em um mundo globalizado. Lua Nova, São Paulo, 77: 11-39, 2009.

GOMES, Nilma Lino. Cultura negra e educação. Revista Brasileira de Educação, n.23, p. 7585, 2003.

. Educação e Relações Raciais: Refletindo sobre Algumas Estratégias de Atuação. In: MUNANGA, Kabengele (Org.). Superando o racismo na escola/Secretaria de Educação Continuada, Alfabetização e Diversidade. 2 ed. Brasília: MEC/SECAD, p. 143-154, 2005.

KOLLER, S. H.; BERNARDES, N. Desenvolvimento moral pró-social: Semelhanças e diferenças entre os modelos teóricos de Eisenberg e Kohlberg. Estudos de Psicologia, p. 223262,1997

MARCHESI, Álvaro. O valor de educar a todos num mundo diverso e desigual. Revista Prelac, n.2, p.54-69, 2006.

MUNIZ, J. O. Sobre o uso da variável raça-cor em estudos quantitativos. Revista Sociologia e Política, v.18, n.36, p.277-291, 2010.

PEREIRA, J. S.. Reconhecendo ou construindo uma polaridade étnico-identitária? Desafios do ensino de história no imediato contexto pós-Lei ${ }^{\circ}{ }^{10.639}$. Estudos Históricos, v.21, n.41, p.2143, 2008.

RAWLS, John. O Liberalismo Político. São Paulo: Editora Ática, 2000a.

. Uma Teoria da Justiça. São Paulo: Martins Fontes, 2000b.

. Justiça como Equidade. Uma Reformulação. São Paulo: Martins Fontes, 2003. 